\title{
Individual Responses in the Domestic Horse Regarding Human Behaviour in Identical Settings
}

\author{
Kathrin Schütz ${ }^{1}$, Annika Rötters ${ }^{2}$ and Lara Oebel ${ }^{2, *}$ \\ 1 Psychology School, Hochschule Fresenius University of Applied Sciences, Platz der Ideen 2, 40476 \\ Düsseldorf, Germany; kathrin.schuetz@hs-fresenius.de \\ 2 Psychology School, Hochschule Fresenius University of Applied Sciences, Im Mediapark 4c, 50670 Köln, \\ Germany; annika.roetters@gmail.com \\ 2 Psychology School, Hochschule Fresenius University of Applied Sciences, Im Mediapark 4c, 50670 Köln, \\ Germany; lara-o@live.de \\ * Correspondence: kathrin.schuetz@hs-fresenius.de; Tel.: +49-211-436915-38
}

\begin{abstract}
Although there has been research regarding the response of horses to human behaviour, there is still a gap concerning the knowledge about the interaction of horses and humans in showing individual responses to different human behaviour in the same situation. In this work, the horses' individual responses to different humans were examined to close this research gap and to identify whether or not horses actually respond differently to different people. To this end, 29 interactions between horses and humans, where the humans were supposed to lead the horse through a training course (including two identical exercises in each situation) were videoed and then transcribed in the style of the action-oriented system of notations HANOS (Handlungsorientiertes Notationssystem). The qualitative content analysis was appropriated on the basis of Mayring. Just nonverbal interactions between each person and one horse were focused. In total, just under 600 interactions were analyzed and categorized. The categories were then put into a chi-square-test (quantitative analyses). Based on these analyses, it can be assumed that each human individual received an individual, different feedback from the horses.
\end{abstract}

Keywords: nonverbal communication; interspecific communication; domestic horse

\section{Introduction}

There have been data supporting the assumption that horses and humans do interact in interspecific communication. Horses have also been used in psychotherapy practice and animal assisted therapy for a long time but there has been less research about the specific horse-human interaction. About a hundred years ago it was claimed that a stallion, known as "Clever Hans", displayed counting, reading, spelling, and even arithmetic skills. Hans was supposed to solve these intellectual tasks by tapping his hoof or moving his head. Pfungst (1911) found that it was not about Hans' specific mental abilities but rather his ability to read his owner's facial expressions. He would react to small, involuntary body movements of the human interacting with him. Those movements initiated and ended Hans' movements. 
Malavasi and Huber (2016) investigated the horses' searching behaviour regarding a treat that was presented first and then hidden in a bucket by one person. Each horse was not able to reach the treat on its own. Then another person entered the setting, which induced the following behaviour of the horse. All horses moved their heads and views from the person to the bucket and back to the person. The researchers interpreted this as an asking for help behaviour. Furthermore, horses were shown two apples being put into a container. Its contents were not visible to the horses. Then three apples were put into another container. The horses could (without prior learning) differentiate between these two containers and headed for the second container.

In a further study, Ringhofer and Yamamoto (2017) examined the horses' ability to adapt their nonverbal communicational behaviour according to the known state of humans. There were two settings. In the first setting, the person interacting with the horse witnessed somebody else hiding a carrot. In the second setting, the carrot was hidden without the interacting person observing. The horses differentiated between knowing and unknowing interaction partners. They increased their visual and tactile efforts to point out the carrot, which was not reachable for the horse, to the unknowing person. This indicates the horses' capability to adjust their behaviour towards different human beings. Schuetz et al. (2017) explored whether horses are able to learn by watching humans. After observing a person pressing a light switch to open a feeding box the horses were able to open this box by pressing the light switch as well. This indicates the horses' cognitive skill to anticipate the result of a certain action.

Proops and McComb (2010) investigated the use of human-given cues by horses. They tested their ability to discriminate between attentive and inattentive persons to obtain food. Some of the available cues were head orientation, body orientation or the opened or closed experimenters' eyes. The horses chose the attentive person more often. Another study explored the differences between adult horses and youngsters (under the age of three) choosing an attentive person to approach for food. Younger horses used body orientation but not other -more subtle- cues to choose a person with a rewarded bucket. Older horses could read other subtle human body cues, like for example opened or closed eyes and head movement.

Horses can therefore be thought to understand human attentional states and modify their auditory or tactile begging behaviour in a food-requesting situation. The results of Takimoto et al. (2016) suggest that they do understand whether the experimenter's eyes were covered by his hand or were not covered. They produced more tactile or auditory begging behaviours when the person's eyes were covered than when they were open. This indicates as well, that horses can be thought to have cognitive conclusions in their interaction with humans. Futhermore, horses are able to rely on four human gesticular cues in an (two-way) object choice task. Food was hidden under one of two bowls and the horses were able to locate the reward by watching the experimenter using one of four cues (Maros, 2008). In another object choice task, horses were able to use marker placement cues and distal sustained pointing spontaneously but not body orientation, momentary tapping and gaze (head) alternation cues (Proops et al., 2010). In this respect it can be concluded that horses can be thought to have the ability to interprete human body language to find food. 
Smith et al. (2016) investigated whether horses are able to spontaneously discriminate between positive and negative human facial expressions in photographs. They showed that pictures of angry faces led to a quicker increase in the horses' heart rate. Furthermore, the researchers discovered a left-gaze bias towards the pictures of angry faces, which they interpreted as a general association with the perception of negative stimuli. This indicates that horses can be thought to be able to differenciate between different human facial expressions and to adjust their behaviour according to the expression of an interacting human.

Other authors dealt with a training program for horses with reward-based operant conditioning. Horses learnt to communicate bay touching different visual symbols to express whether they wanted to have a blanket or not. They could differentiate between three different (neutral) symbols (Mejdell et al., 2016). Hanggi (1999) showed that horses are able to discriminate between an open-center stimulus and a filled black shape (two-dimensional) by operant conditioning (e.g., circle, square, hexagon, flower, star). They touched the correct one with their nose. Correct reactions (choosing opencenter stimuli) were reinforced by food and a positive word, incorrect behaviour (choosing filled stimuli) was not reinforced. In this study the horses were trained to show a certain behaviour which leads to the conclusion that they can be conditioned. Regarding the studies above it can be presumed though that the behaviour of a horse is more complex.

Concerning the lack of scientific foundation whether horses are able to show individual responses to different human behaviour during a complex task (not just facial expression or hiding food), this study was conducted explorative in nature. Previous studies focused on certain behaviours of horses and how it can be provoked. The following study focuses on the question which reactions horses show when they interact with humans in the same settings. The research questions led to a qualitative design.

"Do horses react individually to different people in the same situations? If so, which reactions do they show?"

The aim of this examination was to provide evidence whether horses do show the same behaviour in the same objective setting or adapt their behaviour according to different human interaction partners.

\section{Materials and Methods}

This study was carried out in North Rhine-Westphalia (Germany) between September of 2016 and April 2017. Horse owners were informed of the study's aims. Their participation was voluntary, and they signed an informed consent agreeing to participate in the study.

The sample consisted of 29 people (age range 19-59 years; $M=36.93, S D=11.09$ ). 18 test persons were already experienced in the handling of horses and eleven test persons could not exhibit any experiences with horses. 21 test subjects $(72.41 \%$ of the sample) were female. 
The human subjects interacted in two exercises with the horses $(N=5$; two geldings, three mares; age range 12-18 years), whereby the exercises had an identical layout. Not all human subjects were experienced in horse handling or trained horse handlers. A safety briefing about the handling of animals and horses in specific was mandatory for every test subject. The horses were wearing holsters during the complete task, part of the exercise was to conduct the horses through a certain parcours using a rope attached to the holster. Trained horse handlers were watching every second of the study only meters apart, ready to come into action when needed, but that was not necessary during the study. The subjects were not allowed to carry edible treats for the horses on themselves during the study.

For every interaction two horses were randomly assigned. In the first exercise, the persons were allowed to choose one of the two horses with which they wanted to go through the course after contacting them. The task was to lead the horse on the slalom course around four pylons, followed by bringing the horse to a halt over a rod so that the front legs were in front of the rod and the hind legs were behind it (figure 1).

a

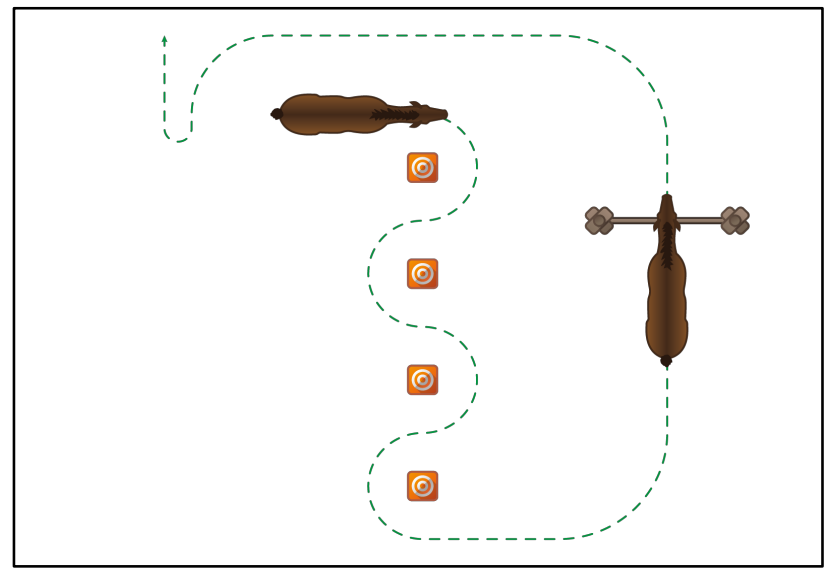

b

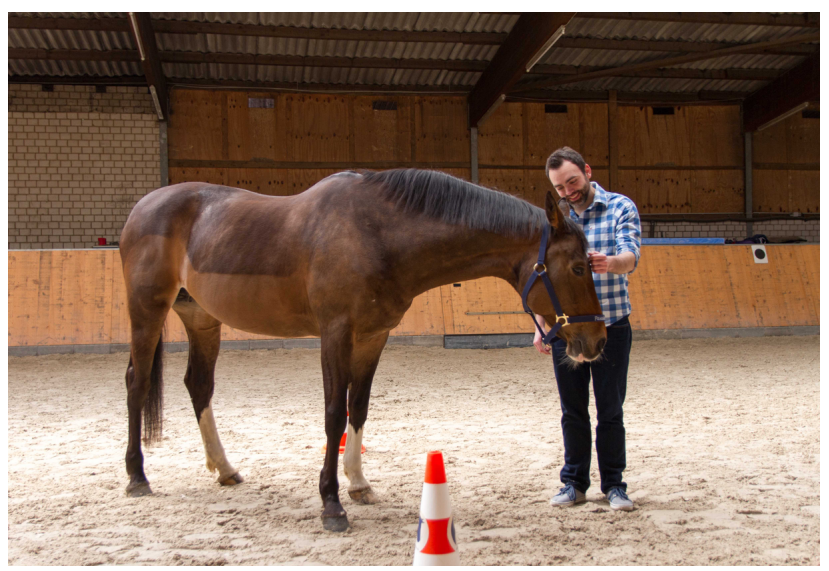

Figure 1. First experimental Setting: a leading task in the first setting (the way the horse was supposed to be led by their human test subjects through a course) $\mathbf{b}$ greeting between a male test subject and a mare

In the second exercise, three pylons were arranged in a triangle. After contacting the horses, the test subjects should supplement this triangle with the chosen horse by another triangle, so a star was built viewed from above (figure 2). The tasks were selected because of their simple design and because the horses were familiar with them having practiced the exercises at least ten times before. This fact was important to be able to examine if horses are just habituated in the known situation or if they react individually to different persons. The test subjects did not know the tasks beforehand. This was important to make sure no human subject could have trained for the tasks earlier. The horses did not know the humans beforehand. Each human participant did each exercise once, with one horse he or she was allowed to choose from a randomly selected pair of horses. There were no repetitions, but two different exercises. Before the second task was built, all human subjects completed the first course. 


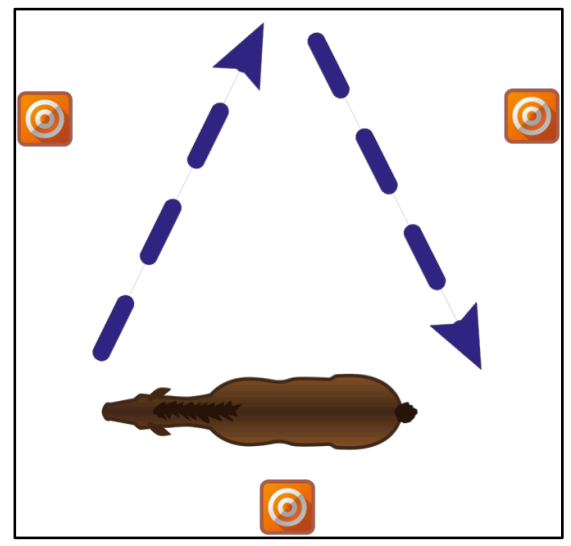

b

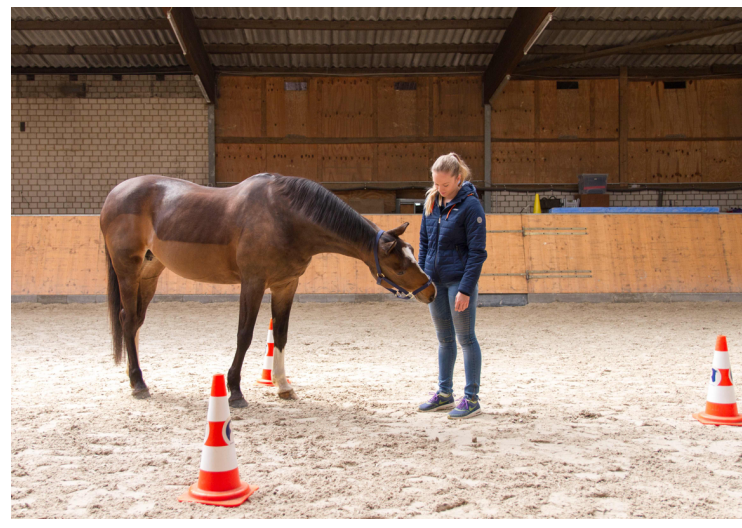

Figure 2. Second experimental Setting: a Leading task in the second setting (the way the horse was supposed to be lead by their human test subjects to supplement a triangle) $\mathbf{b}$ greeting between a female test subject and a mare

Every task was videotaped using a Camcorder (JVC Everio HD model number GZ-HM $30 \mathrm{BE}$ ) on a tripod (Bilora model number 1122). Based on the videotaped exercises and the horses' related reactions to the subjects' behaviour, every interaction between horse and human was transcribed (e.g. movement of the ears, horse turning its head towards the person, horse walking in any direction - leaded or own movement, snorting, snuffeling). They formed the basis for the content analysis and the following inferential statistical analyses. In the present study, no damage was inflicted on the horses.

Within the context analyses, the videos, which included solely the horses' and the subjects' behaviour in the individual tasks, were used. At first, the videos were transcribed focusing on the body language. Spoken language was not written down. Only sequences including direct interactions between the horse and the human were transcribed. The transcription's screenshots and segments were summarized in an Excel table.

The basis for the analyses was the HANOS system ("Handlungsorientiertes NotationsSystem") by Englert (2014), describing not the camera perspectives but the interactions in front of the camera. The subsequent qualitative content analysis (interaction analysis) was performed based on Mayring (2010) because under this method the material can exist in any symbolic manner and the focus is on communication. The analytical steps by Mayring were abided. The first step was to inductively identify categories in form of relevant structural dimensions from the raw data. A deductive procedure was not possible due to the research gap. The first set consisted of 39 categories of horses behaviour (e.g. interest, acceptance, deflection, curiosity, disrespect). The next step was to define the categories (e.g. interest: horse looks at the subject; ears rotated towards the subject). Certain categories showed consisting content, which lead to a reduction to a categorical system including in total eight categories (table 1). By explicating these categories, conditions for the 
classification of certain behaviours into the categorical systems were specified (table 1). Standard examples from the sample were used to ensure methodological traceability (table 1). The last step was to identify conditions for demarcation between similar categories. The identical eight categories were found by each of three independent researchers. For a deeper analysis of the video material the total frequency of occurrences was counted. These data were then analyzed statistically.

\subsection{Statistical Analysis}

The transcription's screenshots and segments were summarized in an Excel table. In the style of HANOS qualitative categories were identified. The data were analyzed with the statistics software IBM SPSS Statistics 24. Chi-square tests of the frequencies of the horses' behaviour in the different settings and of the horses' reactions towards the subjects were applied.

\section{Results}

Analyzing the video material, 594 clear reactions of the horses in answer to the subjects' behaviour could be observed. These could be classified into eight distinct categories (rejection, lack of interest, obedience, limits, interest, fatigue, ambiguity, satisfaction; table 1). In regard to the research question, it can be concluded that the horses were able to recognize body conditions, such as relaxation. The horses reacted to positive (e.g. friendly welcome: slow approximation and careful touching) and negative behaviours (ignoring the horse). If the subjects, for example, radiated selfassurance the horses responded in a congruent manner by standing still or by hesitating to move forward. On friendly gestures towards the horses, such as scratching, the horses responded in a friendly, facing manner by licking their hand or looking for closeness.

Table 1. Categories of the horses' reactions

\begin{tabular}{|c|c|c|}
\hline Category & Description & Example \\
\hline Rejection & $\begin{array}{l}\text { The horse does not } \\
\text { participate. }\end{array}$ & $\begin{array}{l}\text { Horse snuffles the } \\
\text { pylons. }\end{array}$ \\
\hline Lack of interest & $\begin{array}{l}\text { The horse does not } \\
\text { show interest in the } \\
\text { subject. }\end{array}$ & Horse turns away. \\
\hline Obedience & The horse cooperates. & $\begin{array}{l}\text { Horse follows the } \\
\text { subject in the setting. }\end{array}$ \\
\hline Limits & $\begin{array}{l}\text { The horse shows } \\
\text { resistance. }\end{array}$ & Horse does not move. \\
\hline Interest & $\begin{array}{l}\text { The horse shows } \\
\text { interest in the subject. }\end{array}$ & $\begin{array}{l}\text { Horse looks at the } \\
\text { subject; ears rotated } \\
\text { towards the subject. }\end{array}$ \\
\hline
\end{tabular}




\begin{tabular}{cll} 
Fatigue & $\begin{array}{l}\text { The horse shows tired } \\
\text { behaviour. } \\
\text { The horse does not } \\
\text { show any distinct class } \\
\text { of behaviour / offers } \\
\text { different behaviours. } \\
\text { The horse shows signs } \\
\text { of friendly relaxation. }\end{array}$ & $\begin{array}{l}\text { Horse yawns. } \\
\text { sideways, backwards; } \\
\text { seems confused about } \\
\text { the task. }\end{array}$ \\
$\begin{array}{l}\text { Horse licks the } \\
\text { subject's hand, snorts. }\end{array}$ \\
\hline
\end{tabular}

In every individual case of the interaction, the horses reacted differently compared to the other individual cases. They did not show the same behaviour, even though they knew the exercises. This can be considered as an indication that the horses reacted in a different manner, which cannot be explained by the (identical) structure of the exercise.

This can be interpreted as an expression of diverse experienced realities. In the objectively same situation, the horses did not respond uncertainly on uncertainty but expressed their different experiences in diverse ways. It was apparent that the respective horse did no longer follow the subject and stopped, hesitated or changed the direction independently and thus pulled the subject into the direction of choice. The different reactions demonstrate that the horses approached every subject individually.

Based on the previous qualitative analyses, the horses' reactions (8 categories, see table 1) towards the 29 subjects were put into relation by a Chi-square test. The result is highly significant, and it indicates that horses do not react in the same way to different subjects (in the same situation). In other words: The Chi-square test of the frequencies of the horses' behaviour in the different settings showed that the horses' reactions were not equal in the same settings but different in each context with a different human test subject $\left(\chi^{2}(196, \mathrm{~N}=29)=386.71, \mathrm{p}<.001\right)$. The differences were highly significant and prove horses to react distinctly.

Furthermore, there were no significant differences in the frequencies of the horses' reactions between the two tasks as another Chi-square test revealed $\left(\chi^{2}(7, \mathrm{~N}=8)=4.02\right.$, $\mathrm{p}>.05$, n.s.). This means that the mode of exercise did not have a direct influence on the horses' behaviour. The horses did not react more frequently in a special way depending on the two specific exercises.

\section{Discussion}

The presented results strengthen the hypothesis that horses react to objectively identical behaviours in different ways depending on the person who carried out the exercise. The horses investigated in this study were not trained to show a standard behaviour in a specific situation. This supports the theory of Meyer (2008) who claimed that horses are able to reflect human inner processes like for example the emotional state of a person, shown in tiny changes in human body language. If it is indeed a 
reflection and whether the participation of mirror neurons in the horse brain can be a part of the shown behaviour remains yet to be focused on further research.

Evolutionary-biological the horses' behaviour can be explained as critical for the surviving of the species. Horses are gregarious animals known for their preference for flight in critical situations. To secure the survival of the herd, it is important for every horse to be able to rely on the leader. To ensure a reliable leader the leading competencies are constantly verified. If the leader is proven to be unreliable, horses are known to actively change the hierarchy by taking the lead (Greiffenhagen \& BuckWerner, 2007; Krueger et al., 2014). Therefore, horses may be able to distinguish between different human behaviours as well.

Opgen-Rhein (2011) suggested a transfer of the nonverbal abilities regarding the leading horse to a leading human during the process of domestication. According to Opgen-Rhein, horses learnt to react instantly to individual human nonverbal behaviour and are therefore able to interpret human nonverbal behaviour correctly. The previous study supports this suggestion as it shows that horses react differently. If horses are therefore not only able to be of therapeutic use to humans but able to show an objective reflection of human behaviour (Julius et al., 2014; McCormick \& McCormick, 1997; Otterstedt, 2001, 2003; Rockenbauer, 2010; Schultz et al., 2007), due to their suggested ability to interpret human behaviour is yet to be proven. The results of this study support these theories.

The study was conducted in the field; therefore, objectivity and reliability were considerably smaller, whilst the external validity is to be interpreted as much higher than in a laboratory experiment.

\section{Conclusions}

This study supports that horses show different reactions in the same settings due to different human behaviour. Horses are used in several working contexts as for example in therapeutic approaches. It is often explained that horses either show only trained behaviours or can be assumed to anticipate a person's state of mind and affection before an interaction between human and horse takes place. Sometimes, this is reported as a cognitive act. In the present study, the horses also reacted in different manners, even though the exercises were the same and the persons showed similar behaviours. If they did this due to affections, smells or behavioural clues given by the humans remains to be a future research question. These results indicate more significant factors influencing a horse's behaviour than the objective task presented to the horse in the setting. This leads to further questions. If the horses' reactions were not trained before - where does the horses' behaviour come from? Are horses really able to correctly interpret human emotional state? Are they furthermore able to reflect human emotions? (How) Are horses capable of detecting slight differences in human behaviour even other humans do not notice? How is the horses' behaviour influenced by the dynamic of the interaction between human and horse during the whole study? Is the interaction moderated by behaviours shown by the investigators? These questions are to be explored in the future. 
Acknowledgments: This research did not receive any specific grant from funding agencies in the public, commercial, or not-for-profit sectors.

\section{References}

Englert, C.J. Der CSI-Effekt in Deutschland. Springer: Wiesbaden, Germany, 2014.

Greiffenhagen, S.; Buck-Werner, O.N. Tiere als Therapie. Kynos: Mürlenbach, Germany, 2007.

Hanggi, E. Categorization learning in horses (Equus caballus). J Comp Psychol 1999, 113, 243-252, http://dx.doi.org/10.1037/0735-7036.113.3.243.

Julius, H.; Beetz, A.; Kotrschal, K.; Tuner, D.C.; Uvnäs-Moberg, K. Bindung zu Tieren. Hogrefe: Göttingen, Germany, 2014.

Krueger, K.; Flauger, B.; Farmer, K.; Hemelrijk, C. Movement initation in groups of feral horses. Behav Processes 2014, 103, 91-101, https://doi.org/10.1016/j.beproc.2013.10.007.

Malavasi, R.; Huber, L. Evidence of heterospecific referential communication from domestic horses (Equus caballus) to humans. Anim Cogn. 2016, 6029, 899-909, https://doi.org/10.1007/s10071-016-0987-0.

Maros, K; Gácsi, M; Miklósi, A. Comprehension of human pointing gestures in horses (Equus caballus). Anim Cogn. 2008, 11, 457-466, https://doi.org/10.1007/s10071-008-0136-5.

Mayring, P. Qualitative Inhaltsanalyse. Beltz: Weinheim, Germany, 2010.

Mejdell, C.M.; Buvik, T.; Jørgensen, G.H.M.; Bøe, K.E. Horses can learn to use symbols to communicate their preferences, Appl. Anim. Behav. Sci. 2016, 184, 66-73, https://doi.org/10.1016/j.applanim.2016.07.014.

Meyer, S. Pferde als Medium im Coaching: natürlich, ehrlich und nachhaltig! Coaching-Magazin 2009, 4, 42-43.

Opgen-Rhein C. Wirkweisen pferdegestützter Therapie. In Pferdegestützte Therapie bei psychischen Erkrankungen; Opgen- Rhein, C.; Kläschen. M.; Dettling, M., Eds;. Schattauer: Stuttgart, Germany, 2011, pp. 11-22.

McCormick, A.; McCormick, M. Horse Sense and the Human Heart: What Horses Can Teach Us About Trust, Bonding, Creativity and Spirituality. Health Communications: Deerfield Beach, USA, 1997.

Otterstedt, C. Tiere als therapeutische Begleiter. Kosmos: Stuttgart, Germany, 2001.

Otterstedt C. Der heilende Prozess in der Interaktion zwischen Mensch und Tier. In Menschen brauchen Tiere; Otterstedt, C.; Olbrich, E., Eds.; Kosmos: Stuttgart, Germany, 2003, pp. 58-68.

Pfungst, O. Clever Hans (The horse of Mr. von Osten): a contribution to experimental animal and human psychology. Henry Holt: New York, USA, 1911.

Proops, L.; McComb, K. Attributing attention: the use of human-given cues by domestic horses (Equus caballus). Anim Cogn. 2010, 13, 197-205, https://doi.org/10.1007/s10071-009-0257-5.

Proops, L.; Rayner, J.; Taylor, A.M.; McComb, K. The Responses of Young Domestic Horses to Human-Given Cues. PLOS ONE 2013, 8, 1-11, https://doi.org/10.1371/journal.pone.0067000.

Proops, L.; Walton, M.; McComb, K. The use of human-given cues by domestic horses, Equus caballus, during an object choice task. Anim Behav. 2010, 79, 1205-1209, https://doi.org/10.1016/j.anbehav.2010.02.015.

Ringhofer, M.; Yamamoto, S. Domestic horses send signals to humans when they face with an unsolvable task. Anim Cogn. 2017, 20, 397-405, https://doi.org/10.1007/s10071-016-1056-4.

Rockenbauer, S. Tiergestützte Therapie mit Pferden bei Patienten mit emotionaler Instabilität. 2010, http:/othes.univie.ac.at/9529/1/2010-05-04_0401559.pdf (accessed 10 January 2018).

Schuetz, A.; Farmer, K.; Krueger, K. Social learning across species: horses (Equus caballus) learn from humans by observation. Anim Cogn. 2017, 20, 567-573, https://doi.org/10.1007/s10071-016-1060-8.

Schultz, P.N.; Remick-Barlow; G.A.; Robbins, L. Equine-assisted psychotherapy: a mental health promotion/intervention modality for children who have experienced intra-family violence. Health Soc Care Community 2007, 15, 265-271, http://dx.doi.org/10.1111/j.1365-2524.2006.00684.x.

Smith, A.V.; Proops, L.; Grounds, K.; Wathan, J.; McComb, K. Functionally relevant responses to human facial expressions of emotion in the domestic horse (Equus caballus). Biol. Lett. 2016, 12, 20150907, http://dx.doi.org/10.1098/rsbl.2015.0907.

Takimoto, A.; Hori, Y.; Fujita, K. Horses (Equus caballus) adaptively change the modality of their begging behavior as a function of human attentional states, Psychologia 2016, 59, 100-111, https://doi.org/10.2117/psysoc.2016.100. 
Uller, C.; Lewis, J. Horses (Equus caballus) select the greater of two quantities in small numerical contrasts. Anim Cogn. 2009, 12, 733-738, https://doi.org/10.1007/s10071-009-0225-0. 